\title{
Impact of household food insecurity on the nutritional status and the response to therapeutic feeding of people living with human immunodeficiency virus
}

\author{
This article was published in the following Dove Press journal: \\ Patient Preference and Adherence \\ 15 December 2011 \\ Number of times this article has been viewed
}

\author{
Paluku Bahwere ${ }^{1,2, *}$ \\ Hedwig Deconinck ${ }^{3, *}$ \\ Theresa Banda $1, *$ \\ Angella Mtimunil,* \\ Steve Collins ${ }^{1, *}$ \\ 'Valid International, Oxford, United \\ Kingdom; ${ }^{2}$ Center of Research in \\ Epidemiology, Biostatistics, and \\ Clinical Research, School of Public \\ Health, Free University of Brussels, \\ Brussels, Belgium; ${ }^{3}$ Save the Children, \\ Westport, CT, USA \\ *These authors contributed equally \\ to this work
}

Background: The role of household food security (HFS) in the occurrence of wasting and the response to food-based intervention in people living with human immunodeficiency virus (PLHIV), especially adults, is still controversial and needs investigation.

Methods: Face-to-face interviews to collect data for Coping Strategies Index score and Dietary Diversity Score estimation were conducted during a noncontrolled and nonrandomized study assessing the effectiveness of ready-to-use therapeutic food in the treatment of wasting in adults with HIV. Coping Strategies Index score and Dietary Diversity Score were used to determine HFS, and the participants and tertiles of Coping Strategies Index score were used to categorize HFS.

Results: The study showed that most participants were from food insecure households at admission, only $2.7 \%(5 / 187)$ ate food from six different food groups the day before enrolment, and 93\% (180/194) were applying forms of coping strategy. Acute malnutrition was rare among $<5$-year-old children from participants' households, but the average (standard deviation) mid-upper arm circumference of other adults in the same households were 272.7 (42.1) $\mathrm{mm}, 254.8$ (33.8) $\mathrm{mm}$, and 249.8 (31.7) $\mathrm{mm}$ for those from the best, middle, and worst tertile of HFS, respectively $(P=0.021)$. Median weight gain was lower in participants from the worst HFS tertile than in those from the other two tertiles combined during therapeutic feeding phase ( 0.0 [ -2.1 to 2.6$] \mathrm{kg}$ versus 1.9 [ -1.7 to 6.0$] \mathrm{kg} ; P=0.052)$ and after ready-to-use therapeutic food discontinuation $(-1.9[-5.2$ to 4.2$] \mathrm{kg}$ versus $1.8[-1.4$ to 4.7$] \mathrm{kg} ; P=0.098)$. Being on antiretroviral therapy influenced the response to treatment and nutritional status after discontinuation of ready-to-use therapeutic food supplementation.

Conclusion: Food insecurity is an important contributing factor to the development of wasting in PLHIV and its impact on therapeutic feeding response outlines the importance of food-based intervention in the management of wasting of PLHIV.

Keywords: HIV, malnutrition, food security, ready-to-use therapeutic food, chronically sick, antiretroviral

\section{Introduction}

The role of wasting in the increasing risk of death for people living with human immunodeficiency virus (PLHIV) on antiretroviral therapy (ART), or not yet on ART, has been demonstrated in both resource-poor countries and industrialized countries. ${ }^{1-5}$ Recent weight loss or wasting are also predictors of HIV disease progression. ${ }^{6,7}$ However, wasting of PLHIV may result from various factors and food insecurity is probably one of the determinant factors in developing countries, but its role is not yet
Correspondence: Paluku Bahwere Valid International, 35 Leopold Street, Oxford OX4 ITW, United Kingdom Tel +44 I865 722 I 80

Fax +44870 9223510

Email paluku@validinternational.org 
unanimously recognized. Many clinicians still consider that wasting of PLHIV in resource-poor countries is essentially caused by HIV-related inflammatory processes and that effective treatment of HIV and opportunistic infections is sufficient for reversing wasting of PLHIV. ${ }^{89}$ As a consequence, the prevalence of food insecurity among wasted PLHIV has not been sufficiently investigated.

There have been conflicting results on the benefits of food aid for PLHIV. ${ }^{10-12}$ While some studies have found that the provision of food alone using usual humanitarian food baskets has limited impact on nutritional status, quality of life, morbidity, and survival of PLHIV and on the food insecurity of their households, others have demonstrated significant positive effect on the affected individuals or households. ${ }^{10-14}$ Once again, the role of food insecurity in the variation in response to tested interventions has not been sufficiently studied. Thus, the present study was conducted to confirm the high prevalence of household food insecurity among wasted PLHIV from resource-poor countries and to assess the impact of household food security on the response to a therapeutic food-based intervention. The results may help program implementers refine their strategy for addressing wasting in PLHIV.

\section{Methods}

\section{Study design and population}

This was a noncontrolled and nonrandomized trial conducted to assess the effectiveness of chickpea sesame-based readyto-use therapeutic food (CS-RUTF) in reversing wasting in chronically sick adults (CSA) with suspected or confirmed HIV infection. Adults were classified as CSA if they had been ill for three consecutive months. The study had several specific objectives including the determination of weight, midupper arm circumference (MUAC), body mass index (BMI), hemoglobin, and CD4 count gains associated with CS-RUTF supplementation, description of the impact of supplementation on the quality of life and on body composition, and description of individual and household characteristics, including food security, that influence the response to the treatment. A sample size of 300 participants was required to allow accurate estimation of the outcomes mentioned above. The highest sample size was required for the estimation of $\mathrm{CD} 4$ increase. Thus, for sample size calculation we assumed that the $95 \%$ confidence interval width for CD4 count change will be 60 cells $/ \mu$, that the standard deviation of the mean will be 211 and that $70 \%$ of participants will complete the study follow up period. However, only 194 were recruited within the study period and the study could not be extended due to budget constraints. They were recruited from ten participating community-based organizations (CBOs) operating in Mangochi health district (southeast Malawi). Out of the 194, seven were confirmed HIV negative and excluded from the study. Recruitment into the study ran from October 2006 to April 2007. This period coincided with rain and farming seasons, which is also the period of lowest food availability. The target group were CSA with confirmed (positive laboratory test) or unconfirmed (clinical diagnosis without laboratory test confirmation) HIV infection and wasting as defined as mid-upper arm circumference (MUAC) $<220 \mathrm{~mm}$ or Body Mass Index (BMI) $<17 \mathrm{~kg} / \mathrm{m}^{2}$. Community volunteers of the participating CBOs home visited all the CSA supported by their respective CBOs, measured MUAC, and referred to the research team those meeting admission criteria. The research team home visited all referred CSA to confirm eligibility, obtain consent, and enroll those confirmed eligible. The recommended minimum stay in the program was 3 months and the discharge criterion was MUAC $\geq 230 \mathrm{~mm}$. Other types of exit were death, dropout, or exclusion. The criteria for exclusion were hypertension, diabetes, pregnancy, or renal disease.

\section{Measuring household food security}

To assess food security, face-to-face interviews were conducted in the local language of the participants. The interviews were conducted at the homes of the respondents. Information on enrolment into any food aid programs, 24 hours and 7 days food intake recollection, and any adopted food insecurity coping strategies was obtained from the head of the household or his partners using a structured questionnaire. The questionnaire listed the different foods usually consumed in the district and when the food was not directly mentioned by the respondents, the enumerator specifically asked if the food was not consumed.

The parameters used to define the Coping Strategies Index (CSI) included reducing the number of daily meals, skipping an entire day of eating, eating less preferred food, borrowing from relatives or neighbors, purchasing food on credit, and reducing portion size at meal times. ${ }^{10,15,16}$

\section{Dietary Diversity Score (DDS) and CSI}

The information collected was used to calculate DDS and CSI score of the households. ${ }^{16}$ DDS was calculated by summing the number of different categories of food eaten in the 24 hours prior to the interview without frequency weighting as described by Hoddinott. ${ }^{15}$ This method has been shown to be easy to apply, as well as effectively capturing the food security situation of a household. The following twelve foods groups were considered in the calculation of DDS: cereals (bread, nsima, rice, porridge, maheu), roots/tubers (sweet potato, potato, cassava), legumes 
(beans, groundnuts), milk/milk products, fish (dried or smoked fish), poultry (chicken, duck), meat (beef, goat, mice), eggs, fruit (bananas, mango, papaya, avocado, orange), vegetables (tomato, onions, carrots, okra, pumpkin leaf, cabbage, cucumber, mushroom, pumpkin, green vegetable), oils/fats (margarine), sugar and honey, and tea. ${ }^{15} \mathrm{CSI}$ was also calculated using the approach described by Hoddinott. ${ }^{15}$

Each coping strategy was weighted and the frequency of use graded. CSI score was calculated by totaling the weighted sum of each coping strategy (Table 1). The severity of the different coping strategies was estimated by Consortium for Southern Africa Food Security Emergency in Malawi. ${ }^{16}$ A simplified count of frequency was used (never $=2$, sometimes $=1$, almost every day $=0$ ) and six coping strategies were used rather than the 13 used by Consortium for Southern Africa Food Security Emergency. ${ }^{16}$ Thus, CSI for individual households varied from zero to a maximum of 35.5. The higher the CSI score, the more food secure the household.

Food security of the household was further determined by the nutritional status of other adults and children $<5$ years old staying in the same household for whom a MUAC was measured the day of the enrolment of the participant.

\section{Nutritional status}

Nutritional status of adults was measured by MUAC and BMI and the presence of bilateral pitting edema. An adult was classified as wasted if MUAC was $<220 \mathrm{~mm}$ or BMI was $<18.5 \mathrm{~kg} / \mathrm{m}^{2}$. An adult was classified as having edematous malnutrition when he had bilateral pitting edema. For children $<5$ years old, nutritional status was classified using MUAC and presence of bilateral pitting edema. A child with MUAC $<125 \mathrm{~mm}$ or bilateral pitting edema, or both, was classified as having acute malnutrition.

\section{Follow-up, nutritional and clinical assessment, and blood collection}

Subjects were followed up at their homes at 2 weeks, 1 month, and monthly thereafter during therapeutic feeding.

Table I Description of individual coping strategy and weighting

\begin{tabular}{lll}
\hline Coping strategies & Frequency $^{\dagger}$ & Weight \\
\hline Eating less preferred food & $0-2$ & 1.75 \\
Reduce number of meals & $0-2$ & 2.75 \\
Borrowing food & $0-2$ & 2.75 \\
Reducing portion size & $0-2$ & 3.25 \\
Purchasing food on credit & $0-2$ & 3.25 \\
Skipping the entire day without eating & $0-2$ & 4.00 \\
Total & & 35.5 \\
\hline
\end{tabular}

Note: ${ }^{\mathrm{0}} \mathrm{O}=$ almost every day, $\mathrm{I}=$ sometimes, $2=$ never.
After the discontinuation of CS-RUTF supplementation, a quarterly follow-up was continued for 12 months. Similar clinical and nutritional data than those collected at admission were collected at each follow-up and included nutritional assessment, a brief medical history, and physical examination. Blood was taken to measure hemoglobin and CD4 count at admission and at the third monthly follow-up.

\section{Treatment provided}

Interventions for participants included nutrition counseling and education, medical support (treatment for minor diseases and referral), and therapeutic feeding with CS-RUTF from admission to discharge from the program. CSA were eligible for enrolment in the study if they met one of the following criteria: (1) living in the catchment area of a participating $\mathrm{CBO}$, (2) confirmed or presumptive clinical diagnosis of $\mathrm{HIV}$, or (3) MUAC $<220 \mathrm{~mm}$, BMI $<17 \mathrm{~kg} / \mathrm{m}^{2}$, confirmed weight loss $>10 \%$, or bilateral pitting edema of the feet or legs. Diagnosis of HIV was confirmed if the participants had written evidence of HIV testing carried out within the previous 6 months. A presumptive diagnosis of HIV was made if the participant had history or signs of one or several defining conditions of acquired immunodeficiency syndrome without evidence of an HIV-positive test. Untested patients were counseled and referred for HIV testing. HIV diagnosis was confirmed for 37 of the 77 untested, including seven who tested HIV negative. The remaining refused HIV testing or died before HIV testing. Exclusion criteria included diabetes, hypertension, known renal insufficiency, longterm physical disability, or inability to eat. All participants received 3 months supplementary feeding. For those who had MUAC $<230 \mathrm{~mm}$ after the 3 months, supplementary feeding was prolonged for an additional 2 months.

\section{Statistical analysis}

Descriptive statistics (frequency, mean, or median) were used, as appropriate, to describe food security of the households enrolled in the research.

DDS and the CSI scores were used as continuous variables and categorical variables. For both CSI and DDS, tertiles using observed values on admission were created and the tertile cutoff was used to define the categories. The association between household food security and the main outcomes were examined using chi-square (Pearson or Kruskal-Wallis); Student's $t$-test or correlations were used as appropriate. $P$ value $<0.05$ was considered significant for all tests. Means are presented with their standard deviation and medians are presented with their interquartile range. 
Data were entered using Epi Info ${ }^{\mathrm{TM}}$ version 6 (Centers for Disease Control and Prevention, Atlanta, GA). Analyses were carried out using SPSS version 13 (IBM Corporation, Armonk, NY) and Epi Info 6.

\section{Ethical considerations}

The research was authorized by the Malawian National Health Sciences Research Committee and permission was sought and obtained from all participants, who signed a consent form.

\section{Results}

\section{Characteristics of participants}

Sixty-nine percent of participants were women (129/187), the mean age was $34.1(9.2)$ years, $88.2 \%(164 / 186)$ were 18-49 years old, $34.8 \%(65 / 187)$ had never attended school but $56.1 \%$ had attended primary school, $82.9 \%(155 / 187)$ had stopped working because of sickness, and the assessment of activity performance by the Karnofsky score showed that $85.9 \%(159 / 185)$ were unable to perform normal activity or do active work, including $25.4 \%$ (47/185) who were bedridden or required considerable support for carrying out activities of daily living. All were in advanced stage of acquired immunodeficiency syndrome with 39.6\% (74/187) being in World Health Organization clinical stage 3 and 60.4\% (113/187) in clinical stage 4. Not all met CD4 criterion for initiating ART during the study period as only $54.9 \%(84 / 153)$ had CD4 count $<200$ cells $/ \mu \mathrm{L}$. Nutritional status and CD 4 count were similar across all CSI tertiles at enrolment (Table 2).

\section{Household food security status}

Food insecurity was common among the wasted PLHIV enrolled in the study as only $7.5 \%$ (14/187) were not using any of the coping strategies indicative of household food insecurity at admission into the program. CSI score at admission varied from 13.25 to 35.5 . The frequency distribution of the different coping strategies was $87.2 \%(163 / 187)$ for relying on less preferred food or less expensive food, $68.4 \%$ (128/187) for reducing portion size at meal time, 56.1\% (105/187) for reducing the number of meals eaten a day, $37.4 \%$ (70/187) for borrowing food, 36.9\% (69/187) for skipping an entire day without eating, and 20.3\% (38/187) for purchasing food on credit.

The situation did not change during follow-up as demonstrated by Figure 1. The CSI mean was even lower at 2 weeks and 1 month follow-up than at admission. These follow-ups occurred for most of the participants during the height of the hunger season (December, January, and February).
Table 2 Nutritional status, hemoglobin, and CD4 count at enrolment according to the Coping Strategies Index tertile

\begin{tabular}{|c|c|c|c|}
\hline Variables & $\mathbf{n}$ & Mean (SD) & $P$ value \\
\hline \multicolumn{4}{|l|}{ Weight $(\mathrm{kg})$} \\
\hline$\geq 30.0$ & 60 & $41.9(6.9)$ & \multirow{3}{*}{0.468} \\
\hline $22.75-<30.0$ & 58 & $40.5(6.2)$ & \\
\hline$<22.75$ & 62 & $40.8(6.8)$ & \\
\hline \multicolumn{4}{|c|}{ Body mass index $\left(\mathrm{kg} / \mathrm{m}^{2}\right)$} \\
\hline$\geq 30.0$ & 59 & $16.7(2.0)$ & \multirow{3}{*}{0.406} \\
\hline $22.75-<30.0$ & 57 & $16.2(1.8)$ & \\
\hline$<22.75$ & 65 & $16.2(1.9)$ & \\
\hline \multicolumn{4}{|l|}{ MUAC (mm) } \\
\hline$\geq 30.0$ & 63 & $197.8(18.8)$ & \multirow{3}{*}{0.727} \\
\hline $22.75-<30.0$ & 58 & $195.2(18.3)$ & \\
\hline$<22.75$ & 64 & $197.3(19.6)$ & \\
\hline \multicolumn{4}{|c|}{ Hemoglobin $(g / d L)$} \\
\hline$\geq 30.0$ & 54 & $8.6(1.8)$ & \multirow{3}{*}{0.706} \\
\hline $22.75-<30.0$ & 53 & $8.6(2.1)$ & \\
\hline$<22.75$ & 58 & $8.9(2.1)$ & \\
\hline Variables & $\mathbf{n}$ & Median (IQR) & $P$ value \\
\hline \multicolumn{4}{|c|}{$\overline{\text { CD4 count (cells } / \mu \mathrm{L})}$} \\
\hline$\geq 30.0$ & 48 & I58.0 (I04.5-337.0) & \multirow{3}{*}{0.593} \\
\hline $22.75-<30.0$ & 50 & 124.5 (76.5-309.2) & \\
\hline$<22.75$ & 56 & 167.0 (98.7-397.7) & \\
\hline
\end{tabular}

Abbreviations: IQR, interquartile range; MUAC, mid-upper arm circumference; SD, standard deviation.

DDS ranged from one to six food groups, but only $2.6 \%(5 / 194)$ ate food from six different food groups the day before enrolment. The most common pattern was eating food from three different food groups which represented $40.7 \%$ (79/194) of all participants. The DDS mean was similar for the different CSI tertiles.

At admission, there was no correlation between CSI score and MUAC on admission $\left(\mathrm{r}_{\mathrm{s}}=0.080 ; P=0.280\right)$, but there was a low positive correlation between MUAC on admission and DDS $\left(\mathrm{r}_{\mathrm{s}}=0.194 ; P=0.008\right)$.

\section{Nutritional status of other household members}

Out of the 60 children $<5$ years old from 42 households assessed, only two had MUAC $<125 \mathrm{~mm}$ and there were no bilateral nutritional edema cases. The mean MUAC was $150.6(14.0) \mathrm{mm}$. The repartition of the MUAC $<125 \mathrm{~mm}$ children in food security categories defined by CSI tertile was one in the best food security category (30-30.5) and one in the middle category (22.75-29.9). The mean MUAC was 150.3 (13.9), 152.8 (14.7), and 150.0 (13.7) for first tertile (CSI $=30-30.5)$, second tertile $(\mathrm{CSI}=22.75-29.9)$, and third tertile $(\mathrm{CSI}<22.75)$, respectively $(P=0.818)$. Nutritional status of other adults from the same household as 


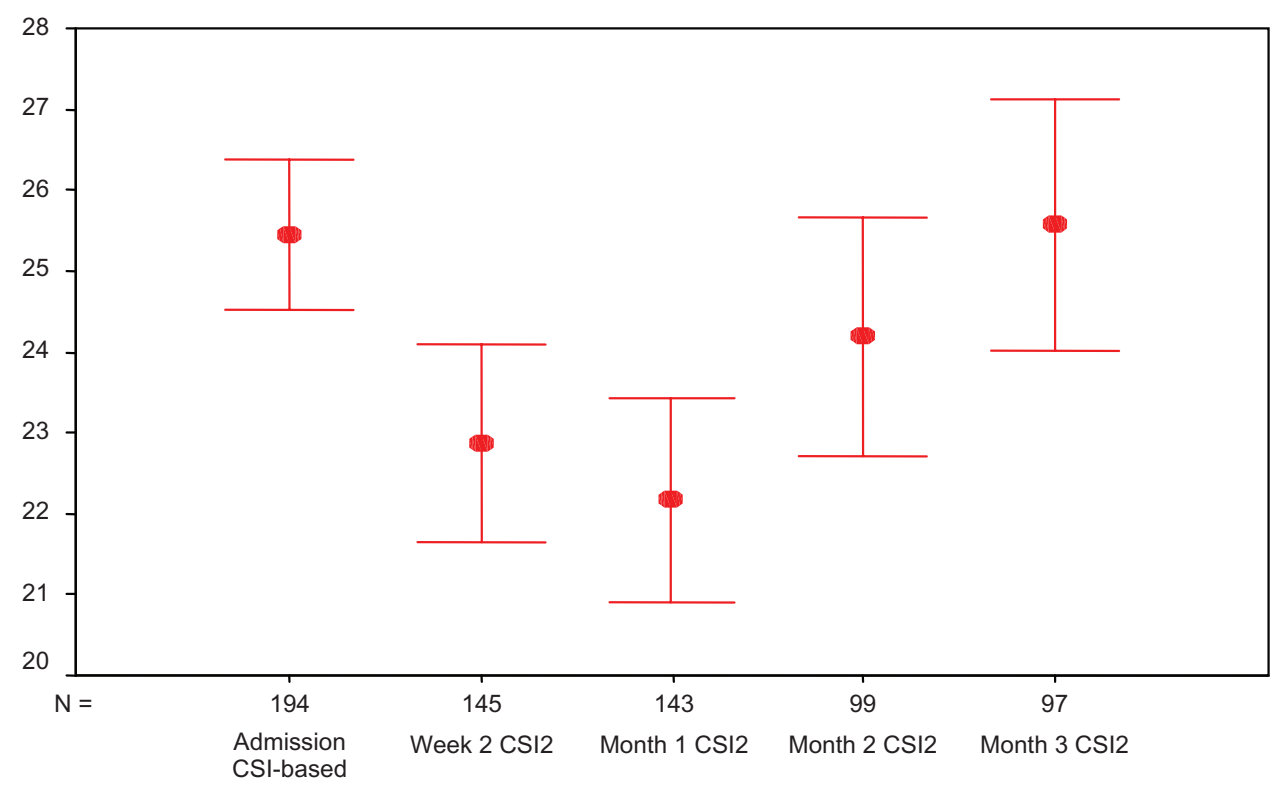

Figure I Coping Strategy Index (CSI) score at admission and follow up visits.

Note: Red bars show $95 \%$ confidence interval.

the participants varied significantly according to CSI tertile. The mean MUAC was 272.2 (42.1) mm, 254.8 (33.8) mm, and 249.8 (31.7) $\mathrm{mm}$ for the first, second, and third tertiles, respectively $(P=0.021)$. The mean BMI was $22.2(3.9) \mathrm{kg} / \mathrm{m}^{2}$, $20.8(3.3) \mathrm{kg} / \mathrm{m}^{2}$, and $20.4(3.4) \mathrm{kg} / \mathrm{m}^{2}$ for the first, second, and third tertiles, respectively $(P=0.080)$.

The proportion of wasting among other adults from participant households varied according to CSI tertile, but the difference was significant only when wasting was defined by BMI $<18.5 \mathrm{~kg} / \mathrm{m}^{2}$ (Figure 2 ).

\section{Acceptability and intake of CS-RUTF}

The acceptability of CS-RUTF was similar in all CSI tertiles. The proportion of those for whom the daily intake of CS-RUTF was $\geq 250 \mathrm{~g}$ was $31.5 \%$ (22/70) for those from the least food secure households, $50.0 \%$ (30/60) for those from the middle CSI tertile, and $43.7 \%(28 / 64)$ for those from the most food secure households $(P=0.088)$.

There was no association between household food security and average CS-RUTF intake. The mean total consumption of CS-RUTF per patient while in the program was 24.7 (17.7) $\mathrm{kg}$ of CS-RUTF and 24.0 (16.3) kg, 25.9 (16.9) kg, and 24.3 (187.6) $\mathrm{kg}$ for the most food secure, middle, and least food secure tertiles, respectively (analysis of variance $P=0.842$ ).

\section{Response to therapeutic feeding}

Nutrition and immunological response to therapeutic feeding differed according to the CSI tertile on admission. The analysis included all participants who had at least one follow-up measurement $(n=160)$. The difference was close to statistical significance for median weight gain $(0.0$ [-2.1 to 2.6$] \mathrm{kg}$ for CSI $<22.75$ versus 1.9 [ -1.7 to 6.0$] \mathrm{kg}$ for $\mathrm{CSI} \geq 22.75$; $P=0.052)$ and median BMI $\left(0.0[-0.9\right.$ to 0.9$] \mathrm{kg} / \mathrm{m}^{2}$ for $\mathrm{CSI}<22.75$ versus 0.7 [ -0.7 to 2.3$] \mathrm{kg} / \mathrm{m}^{2}$ for $\mathrm{CSI} \geq 22.75$; $P=0.058$ ), but not for MUAC, hemoglobin, and CD4 counts (data shown). Higher but not statistically significant differences were observed in the subsample of those who stayed in the program for the minimum recommended 3 months, especially in those not yet on ART (Table 3).

The overall mortality was $45.7 \%(32 / 70)$ for those from least food secure households and 33.1\% (41/124) for those from the middle and the highest tertile $(P=0.217)$.

\section{Nutritional status at the end of 12 months follow-up after discharge from therapeutic feeding phase}

Table 4 shows that after discontinuation of therapeutic feeding with CS-RUTF, participants from the least food secure households who did not start ART lost $5 \mathrm{~kg}$ of body weight while those from more food secure households continued to gain weight in the absence of ART initiation. Weight gain after discontinuation of CS-RUTF in those who ever started ART supplementation did not differ according to the category of food security of the household.

Overall mortality during the 12 months of follow-up after therapeutic feeding discontinuation was $28.9 \%$ (24/83). Mortality during follow-up after discharge from therapeutic 


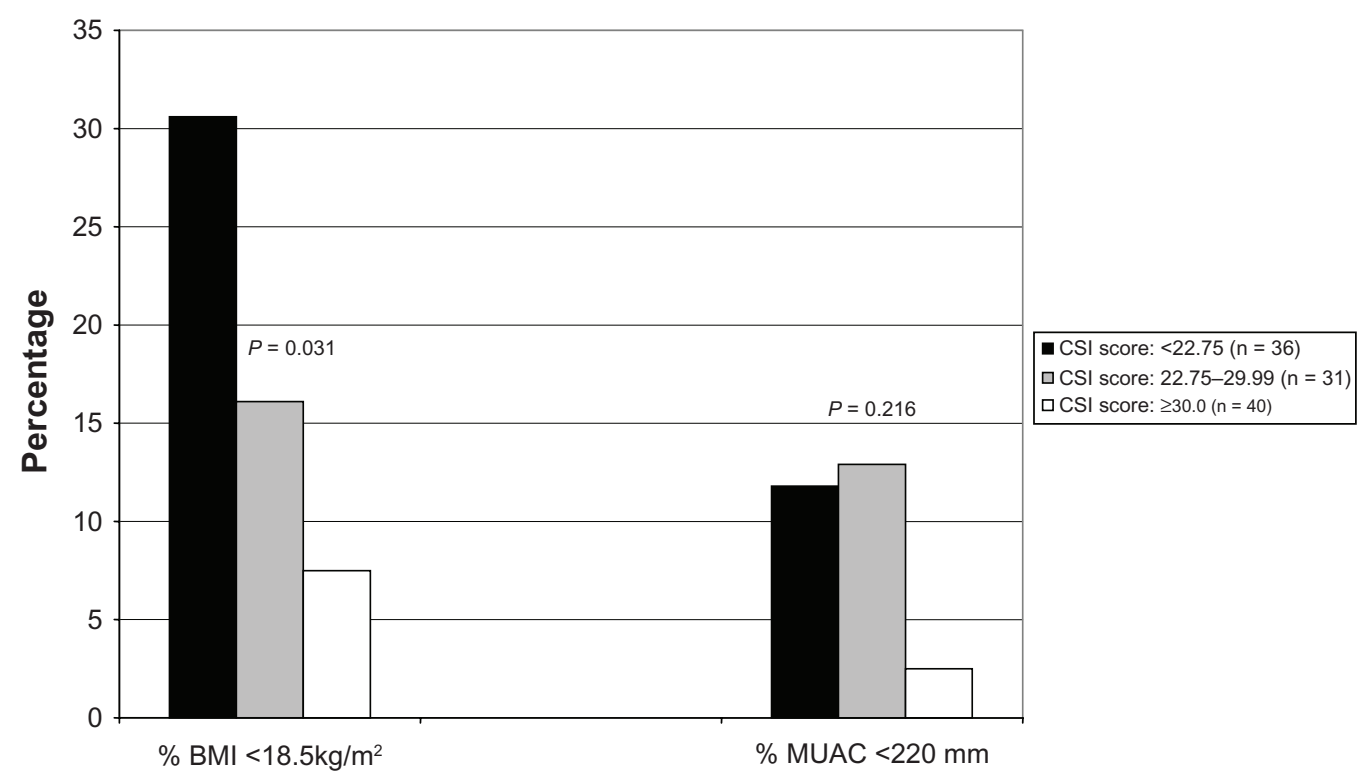

Figure 2 Proportion of wasted adults in the households of the participants according to Coping Strategy Index category. Abbreviations: BMI, body mass index; CSI, Coping Strategy Index; MUAC, mid-upper arm circumference.

feeding phase was neither influenced by the household food security situation on enrolment into the therapeutic feeding phase $(9 / 28$ [32.1\%] from the worst tertile versus $15 / 55$ [27.3\%] from the combined best two tertiles; $P=0.644$ ) nor by ART enrolment (13/47 [27.7\%] among those who started ART versus $11 / 36$ [30.6\%] who never started; $P=0.773$ ).

\section{Discussion}

The study aimed to assess the household food security characteristics of wasted PLHIV and determine the prevalence of food insecurity and the effect of the household food security on the response to therapeutic feeding. In addition to confirming that food insecurity plays a role in the occurrence of wasting in PLHIV in resource-poor countries, results show that PLHIV suffer more from food insecurity than even children $<5$ years old and that wasting can occur in PLHIV from relatively food secure households. Importantly, the results suggest that targeted therapeutic feeding alone may not be sufficient for wasted PLHIV from severe food insecure households.

The capacity of CSI tertiles to capture household food security characteristics of participants in the present study was suggested by the relationship between the tertile of CSI score and the nutritional status of household members, especially adults. Thus, it can confidently be said that in some participants, availability of food at the household level played an important role in the development of wasting. This finding is not surprising as many studies in Malawi and elsewhere show that households of PLHIV have a higher risk of food insecurity. ${ }^{10,17-19}$ The presence of chronic infection and frequent opportunistic infections reduce food production and/or purchasing power capacity. ${ }^{17}$ As a consequence, not only is the availability of the food reduced but also the capacity of diversifying food intake is affected, which exposes PLHIV to multiple micronutrient deficiencies. . $^{10,20}$

This study has also shown that PLHIV may be more vulnerable to the consequence of food insecurity than young children. This suggests that in countries and areas heavily affected by HIV, nutrition surveys should not be restricted to $<5$-year-old children but should also include adults. The increased vulnerability of PLHIV is explained by the fact that limited food access is superimposed to a preexisting level of anorexia induced by systemic inflammatory response to chronic HIV infection. ${ }^{21}$

Other important findings of this study, which have implications for practical programming, include the poor response to therapeutic feeding of participants from the tertile of worst food security and the significant weight loss that occurred when supplementation was discontinued before ART initiation. Contrary to findings based on selfreported intake showing equivalent intake and acceptability of CS-RUTF, these findings suggest that in households with severe food insecurity, CS-RUTF supplement was probably shared among the members of the households more than in households with less food insecurity. CS-RUTF was offered at an amount of $2600 \mathrm{kcal}$, enough to meet the daily nutritional requirement of the targeted wasted CSA. This finding supports the need to combine the provision of therapeutic food with nutritional support in the form of household food 


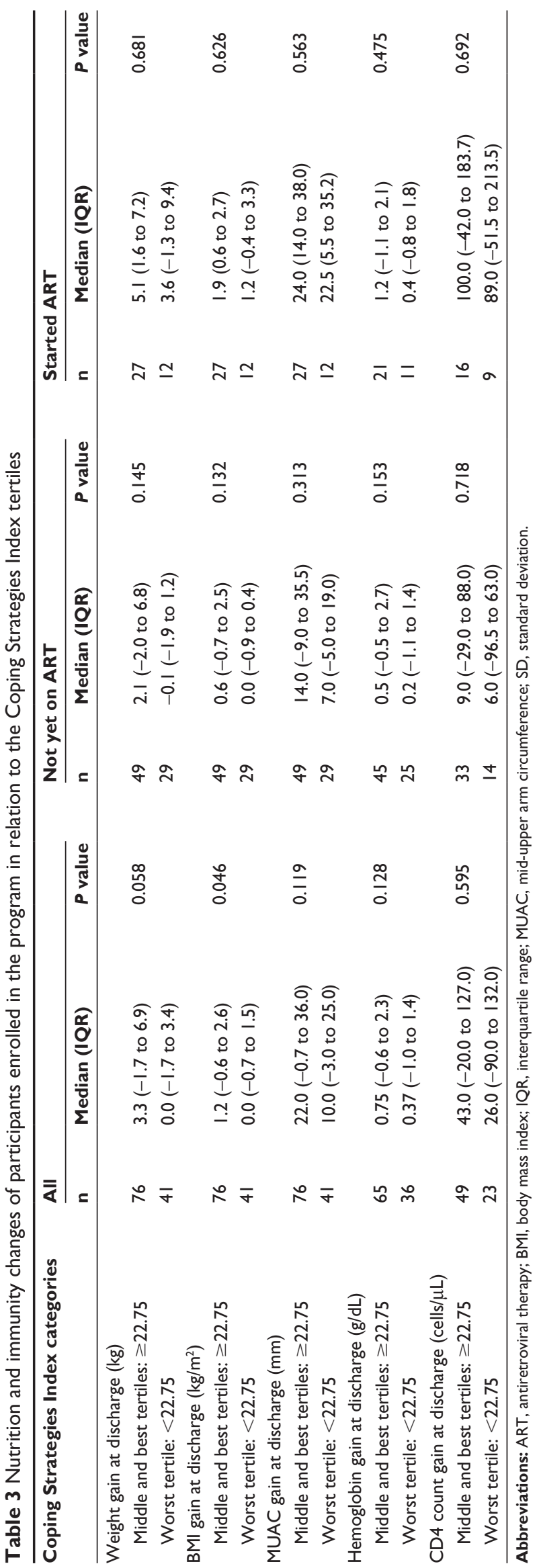

rations during the therapeutic feeding phase in households facing severe food insecurity.

Body weight loss that occurred after the discontinuation of supplementation for beneficiaries not yet on ART from the same households with severe food insecurity confirms that the supplement was preventing rapid deterioration and contributing to a significant proportion of the daily intake despite sharing the supplement with other household members. This is also in accordance with the finding that the food security situation of participant households did not improve during the survey period. These findings suggest that continuation of food support may not be needed after therapeutic feeding phase for wasted PLHIV households with relatively good food security or those who have initiated ART, but some type of supplementation should continue until the patient is started on ART for those from households with severe food insecurity. For that purpose, the effectiveness of using fortified blended food (eg, corn soy fortified blended food) for the continuation of nutritional support should be evaluated.

There have been contrasting results on the impact of food-based interventions in preventing or reversing wasting in PLHIV. ${ }^{14}$ Some studies suggested that such intervention improved nutritional status of PLHIV while others failed to demonstrate any positive impact. ${ }^{14,22}$ The findings of the present study suggest that difference in baseline household food security, not assessed in most of these studies, may explain the contrasting results. It is possible that the underlying household food security situation included in the studies that showed positive impact deteriorated less than those included in the studies that showed no impact. Thus, it will be important for future researches to always consider the baseline household food security of surveyed households and individuals when interpreting the results of a study assessing a therapeutic food-based intervention for PLHIV.

The occurrence of wasting among PLHIV from households with relatively good food security suggests that not only availability but also the quality of food available may be playing an important role in the development of wasting. It supports the use of fortified food and high energy dense food, especially after an episode of severe acute body weight loss. Acute weight loss in PLHIV occurs generally during episodes of opportunistic infections, such as tuberculosis, which increase nutrient and energy requirements while decreasing the appetite already affected by the chronic HIV infection. ${ }^{23}$ It is likely that during such a period only an energy and nutrient dense food can help prevent or reverse severe wasting in these individuals with reduced food intake, even for individuals from less food insecure households. ${ }^{24}$ 
Table 4 Weight gain after discontinuation of CS-RUTF supplementation according to the food security condition at enrolment

\begin{tabular}{|c|c|c|c|c|c|}
\hline \multirow[t]{2}{*}{$\begin{array}{l}\text { Coping Strategy } \\
\text { Index categories }\end{array}$} & \multirow[t]{2}{*}{$\mathbf{n}$} & \multicolumn{2}{|c|}{$\begin{array}{l}\text { Follow-up duration after stopping } \\
\text { CS-RUTF supplementation (days) }\end{array}$} & \multicolumn{2}{|c|}{$\begin{array}{l}\text { Weight change after stopping } \\
\text { CS-RUTF supplementation(kg) }\end{array}$} \\
\hline & & Mean (SD) & $P$ value & Mean (IQR) & $P$ value \\
\hline \multicolumn{6}{|l|}{ All participants } \\
\hline$\geq 22.75$ & 47 & $338.5(117.1)$ & 0.860 & $1.8(-1.4$ to 4.7$)$ & 0.098 \\
\hline$<22.75$ & 21 & $332.8(138.6)$ & & $-1.9(-5.2$ to 4.2$)$ & \\
\hline \multicolumn{6}{|l|}{ Never started ART } \\
\hline$\geq 22.75$ & 20 & $312.9(140.6)$ & 0.595 & I.I ( $(-3.5$ to 3.1$)$ & 0.006 \\
\hline$<22.75$ & 8 & $343.0(112.3)$ & & $-5.2(-7.5$ to -1.9$)$ & \\
\hline \multicolumn{6}{|l|}{ Ever started ART } \\
\hline$\geq 22.75$ & 27 & $357.5(94.5)$ & 0.520 & 3.3 (-9.0 to 5.1$)$ & 0.874 \\
\hline$<22.75$ & 13 & 326.5 (156.8) & & $3.0(-3.2$ to 5.4$)$ & \\
\hline
\end{tabular}

Abbreviations: ART, antiretroviral therapy; CS-RUTF, chickpea sesame-based ready-to-use therapeutic food; IQR, interquartile range.

There are limitations in this study that need to be considered. In the context of this study it was difficult to implement a randomized controlled trial as wasting CSA requiring therapeutic feeding were targeted and two different types of fortified food were used, with one assumed to be inferior to another (not authorized by the head of CBOs). The absence of a control group is another limiting factor. For example, although the results give some insight to the effect of supplementation in the absence of ART, the absence of randomization limits the interpretation. Despite implementing the study in a health district with one of the highest prevalence of HIV, a house-to-house visit in the catchment area of three of the ten participating CBOs showed that the study was not missing eligible participants. Unfortunately, it is worth mentioning that the research started during the course of a supplementation program that had already recruited 250 participants who could have been eligible in this study. Confirmation of the intake was solely based on feedback from the participants. Thus, the real intake and level of intrahousehold sharing was unable to be confirmed. The study was conducted at the beginning of the national scale-up of free ART; however, acceptance of ART is still low in rural communities of Malawi, which explains the high proportion of participants who did not start ART despite being counseled and offered transport fees. ${ }^{25,26}$ This increased the mortality rate among participants, even in those who nutritionally improved. Finally, the high dropout rate also reduced the power of the study. It was not anticipated that many of the participants who improved would return to town to resume their usual activities prior to illness.

\section{Conclusion}

Household food insecurity is a contributing factor to the development of wasting in PLHIV from developing countries and its impact on therapeutic feeding outlines the importance of food-based interventions in the management of wasting of PLHIV and the necessity to address both the individual need of the wasted patients and the food security of their households. Therefore, programs aimed at providing nutritional support should combine food security and anthropometric indicators for selecting beneficiaries of food and nutrition interventions, and both household food package and special energy and micronutrient-dense food (therapeutic food) should be available. However, these findings need to be further confirmed by other studies given the limitations listed above.

\section{Acknowledgments}

The authors would like to acknowledge the invaluable assistance of Save the Children Malawi office and staff and all the program participants and their families. They also acknowledge the great contribution of all Valid International Malawi staff for the success of the study. Special thanks to Laura Banks for editing the manuscript. Funding for this work was provided by Save the Children United States. All authors contributed to the design, implementation, interpretation of the findings, and write up. Written consent for publication was obtained from the patients.

\section{Disclosures}

Hedwig Deconinck had no competing interest. But all the authors work for Valid International, a sister company to Valid Nutrition, a charity organization that promotes local production of ready-to-use therapeutic food. Steve Collins is also an unpaid director of Valid Nutrition. The chickpea sesame-based ready-to-use therapeutic food used for the study was bought from Valid Nutrition in Malawi with funding from Save the Children United States. 


\section{References}

1. Castetbon K, Anglaret X, Toure S, et al. Prognostic value of crosssectional anthropometric indices on short-term risk of mortality in human immunodeficiency virus-infected adults in Abidjan, Cote d'Ivoire. Am J Epidemiol. 2001;154(1):75-84.

2. Schwenk A, Beisenherz A, Romer K, Kremer G, Salzberger B, Elia M. Phase angle from bioelectrical impedance analysis remains an independent predictive marker in HIV-infected patients in the era of highly active antiretroviral treatment. Am J Clin Nutr. 2000;72(2):496-501.

3. Tang AM. Weight loss, wasting, and survival in HIV-positive patients: current strategies. AIDS Read. 2003;13(12 Suppl):S23-S27.

4. Tang AM, Jacobson DL, Spiegelman D, Knox TA, Wanke C. Increasing risk of $5 \%$ or greater unintentional weight loss in a cohort of HIV-infected patients, 1995 to 2003. J Acquir Immune Defic Syndr. 2005;40(1):70-76.

5. van der Sande MA, Schim van der Loeff MF, Aveika AA, et al. Body mass index at time of HIV diagnosis: a strong and independent predictor of survival. J Acquir Immune Defic Syndr. 2004;37(2):1288-1294.

6. Malvy E, Thiebaut R, Marimoutou C, Dabis F. Groupe d'Epidémiologie Clinique du Sida en Aquitaine. Weight loss and body mass index as predictors of HIV disease progression to AIDS in adults. Aquitaine cohort, France, 1985-1997. J Am Coll Nutr. 2001;20(6):609-615.

7. Wheeler DA, Gibert CL, Launer CA, et al. Weight loss as a predictor of survival and disease progression in HIV infection. Terry Beirn Community Programs for Clinical Research on AIDS. J Acquir Immune Defic Syndr Hum Retrovirol. 1998;18(1):80-85.

8. Coodley GO, Loveless MO, Merrill TM. The HIV wasting syndrome: a review. J Acquir Immune Defic Syndr. 1994;7(7):681-694.

9. Lawn SD, Harries AD, Wood R. Strategies to reduce early morbidity and mortality in adults receiving antiretroviral therapy in resource-limited settings. Curr Opin HIV AIDS. 2010;5(1):18-26.

10. Bukusuba J, Kikafunda JK, Whitehead RG. Food security status in households of people living with HIV/AIDS (PLWHA) in a Ugandan urban setting. Br J Nutr. 2007;98(1):211-217.

11. Kadiyala S, Gillespie S. Rethinking food aid to fight AIDS. Food Nutr Bull. 2004;25(3):271-282.

12. Bahwere P, Sadler K, Collins S. Acceptability and effectiveness of chickpea sesame-based ready-to-use therapeutic food in malnourished HIV-positive adults. Patient Pref Adherence. 2009;3:67-69.

13. Maina GW, Gardner CF, Murphy E, Ssemwanga J, Basalirwa J, Magezi SR. Nutritional impact of the Title II feeding program targeting people living with and affected by HIV/AIDS in Uganda. 2005. Available from: http://www.wishh.org/nutrition/countryactivities/ nutritional_impact-uganda.pdf. Accessed November 9, 2011.

14. Koethe JR, Chi BH, Megazzini KM, Heimburger DC, Stringer JS. Macronutrient supplementation for malnourished HIV-infected adults: a review of the evidence in resource-adequate and resource-constrained settings. Clin Infect Dis. 2009;49(5):787-798.
15. Hoddinott J. International Food Policy Research Institute. Choosing outcome indicators of household food security. Mar 1999. Available from: http://motherchildnutrition.org/nutrition-protection-promotion/ pdf/mcn-household-food-security.pdf. Accessed November 9, 2011.

16. Caldwell R, Seroussi M, Hagens C, Huddle J, Mbizule C, Uny K. C-SAFE, TANGO International. Malawi Baseline Survey: report of findings. Sept 2003. Available from: http://www.sarpn.org/documents/ d0000524/C-Safe_Malawi_Report.pdf. Accessed November 9, 2011.

17. Bollinger L, Stover J, Palamuleni ME. Futures Group International. The economic impact of AIDS in Malawi. 2000. Available from: http://allafrica.com/download/resource/main/main/id/00010518.pdf. Accessed November 9, 2011.

18. Donovan C, Massingue J. Illness, death, and macronutrients: adequacy of rural Mozambican household production of macronutrients in the face of HIV/AIDS. Food Nutr Bull. 2007;28(2 Supp1):S331-S338.

19. Palamuleni ME, Kambewa PS, Kanzandira J. Impact of HIV/AIDS on food security: the case of affected and infected urban households in Malawi. Paper presented at: International Working Meeting of Food Africa; May 5-9, 2003; Cameroon. Abstract available from: http:// foodafrica.nri.org/security/cameroonabstracts/PatrickKambewa.pdf. Accessed November 9, 2011.

20. Tontisirin K, Nantel G, Bhattacharjee L. Food-based strategies to meet the challenges of micronutrient malnutrition in the developing world. Proc Nutr Soc. 2002;61(2):243-250.

21. Bistrian BR. Role of the systemic inflammatory response syndrome in the development of protein-calorie malnutrition in ESRD. Am J Kidney Dis. 1998;32(6 Suppl 4):S113-S117.

22. Bowie C, Kalilani L, Marsh R, Misiri H, Cleary P, Bowie C. An assessment of food supplementation to chronically sick patients receiving home based care in Bangwe, Malawi: a descriptive study. Nutr J. 2005;4:12.

23. Macallan DC, Noble C, Baldwin C, Foskett M, McManus T, Griffin GE. Prospective analysis of patterns of weight change in stage IV human immunodeficiency virus infection. Am J Clin Nutr. 1993;58(3):417-424.

24. Stack JA, Bell SJ, Burke PA, Forse RA. High-energy, high-protein, oral, liquid, nutrition supplementation in patients with HIV infection: effect on weight status in relation to incidence of secondary infection. J Am Diet Assoc. 1996;96(4):337-341.

25. Zachariah R, Harries AD, Manzi M, et al. Acceptance of anti-retroviral therapy among patients infected with HIV and tuberculosis in rural Malawi is low and associated with cost of transport. PLoS One. 2006;1:e121.

26. Zachariah R, Tayler-Smith K, Manzi M, et al. Retention and attrition during the preparation phase and after start of antiretroviral treatment in Thyolo, Malawi, and Kibera, Kenya: implications for programmes? Trans R Soc Trop Med Hyg. 2011;105(8):421-430.
Patient Preference and Adherence

\section{Publish your work in this journal}

Patient Preference and Adherence is an international, peer-reviewed, open access journal focusing on the growing importance of patient preference and adherence throughout the therapeutic continuum. Patient satisfaction, acceptability, quality of life, compliance, persistence and their role in developing new therapeutic modalities and compounds to

\section{Dovepress}

optimize clinical outcomes for existing disease states are major areas of interest. This journal has been accepted for indexing on PubMed Central. The manuscript management system is completely online and includes a very quick and fair peer-review system. Visit http://www.dovepress.com/ testimonials.php to read real quotes from published authors. 